\title{
Emergency department crowding: why do patients walk-in?
}

\section{Edmond Brasseur, Allison Gilbert, Jean-Christophe Servotte, Anne-Françoise Donneau, Vincent D'Orio \& Alexandre Ghuysen}

To cite this article: Edmond Brasseur, Allison Gilbert, Jean-Christophe Servotte, Anne-Françoise Donneau, Vincent D'Orio \& Alexandre Ghuysen (2019): Emergency department crowding: why do patients walk-in?, Acta Clinica Belgica, DOI: 10.1080/17843286.2019.1710040

To link to this article: https://doi.org/10.1080/17843286.2019.1710040

册 Published online: 30 Dec 2019.

Submit your article to this journal $\pi$

山 Article views: 83

Q View related articles $\asymp$

View Crossmark data 


\title{
Emergency department crowding: why do patients walk-in?
}

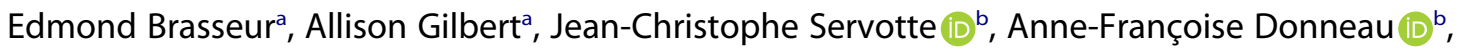 \\ Vincent $D^{\prime}$ Orio $^{\mathrm{a}, \mathrm{c}}$ and Alexandre Ghuysen ${ }^{\mathrm{a}, \mathrm{b}}$
} aEmergency Department, Liege University Hospital Centre, Liège, Belgium; 'bepartement of Public Health, University of Liège, Liège,
Belgium; 'Medicine Faculty, University of Liege, Liège, Belgium

\section{ABSTRACT}

Objectives: For years, general practitioners (GP) shortage and patients' increasing demand for acute care have been associated with Emergency Department (ED) crowding. Indeed, EDs admissions for non-emergency care seem to constantly increase. Surprisingly, the rationale for patients own decision to directly reach EDs over primary care have been poorly investigated to date.

Methods: We conducted a study on patients admitted in two University EDs during nine consecutive days. Patients were asked to answer a survey about their frames for coming and if they were self-referred, referred by a GP, a specialist or after calling the Emergency Number. Results: During the study period, $68.0 \%$ of patients were self-referred, $17.0 \%$ referred by their GP, $8.5 \%$ by a specialist and $7 \%$ after an emergency call. $51.0 \%$ of the self-referrals thought EDs were the appropriate location to deal with their health problem and $24.0 \%$ because of a better accessibility. We noticed that $15.0 \%$ of the incomings looked for specialized care and $4.22 \%$ reported that the stress had motivated them. Of note, $4.6 \%$ of the patients were attracted by the hospital reputation. Financial concerns represented less than $1.0 \%$ of the motives invocated.

Conclusion: We found that patients' self-perceived severity of illness is the predominant frame to each the ED when they face needs for acute care. EDs' accessibility as compared with other facilities also seems to encourage patients to come to the ED. Other factors such as the hospital reputation or patients' stress tend to influence ED attendance but to a much lesser extent.

\section{KEYWORDS}

Emergency Department; overcrowding; primary care; motives; admissions

\section{Introduction}

For years, Emergency Departments (ED) have been confronted to severe overcrowding issues as the result of patient boarding and the lack of available hospital beds mainly making it difficult to deal with the persistent increase of ED patient's inflows. Overcrowding, in turn, has been demonstrated to increase waiting times, emergency practitioners' workload, delay care, increase morbidity and, unfortunately, mortality [1]. While trying to manage those patient's flows, emergency physicians have come to the point of questioning what could be walk-in patients own frames and motivations to come to the ED rather than to primary care physician (PCP) facilities, in particular, for nonemergent situations.

Accordingly, a 2016 Belgian KCE report has proposed to distinguish different kinds of ED incoming populations according to the acuity and severity of their complaints and gain a better understanding of patients' flow. Thereby, patients could be recognized as requiring emergency care, being in need for urgent care or present non-urgent conditions. These latter patients may sometimes represent a major contributor to ED crowding. Diverting those patients to PCP care facilities could indeed alleviate ED workload substantially [2].

For many reasons in most European countries, the organization of primary healthcare has promoted consultations by appointment rather than unscheduled consultations which, accordingly, tend to represent a smaller part of PCPs' global activity. During out-ofhours periods, some PCPs may assume continuity of care every day for all their patients, but more frequently PCPs choose to work in cooperatives covering specific areas. Alternately, primary health-care facilities are also available during out-of-hours periods and patients free to attend by themselves or after a triage phone call with a nurse or a physician [3].

Given these various health-care alternatives, there is still debate on the rationale for the choice made by a large amount of walk-in patients to reach an ED directly, without any prior contact with primary healthcare or triage systems. Indeed, it has been suggested that several factors might influence that decision such as the lack of PCPs or difficulties to get access to primary care facilities but also patients perception of their illness severity, while patient's consideration does not always appear to match physicians' opinions [4-6]. 
In this study, we aimed to determine the drivers and rationale motivating walk-in patients to reach the ED rather than use primary care resources.

\section{Methods}

\section{Study setting and population}

This study was conducted in two facilities of the University Hospital of Liège, the Notre Dame des Bruyères (CHUNDB) site and the Sart Tilman (CHUST) site. ED census in CHUST and CHUNDB is around 50,000 ED patients per year. CHUST is a tertiary care ED located in the suburban area of Liege, while CHUNDB is located in more urban zones and is a secondary hospital.

Practically, during nine consecutive days, in March 2017, data concerning ED incoming patients were gathered. We identified all walk-in adult patients admitted in the ED, either self-referred, referred by a PCP or following a primary care nurse telephone triage as eligible for the study. Likewise, all children who were seeking care at the ED and presented with a relative were eligible to participate in the study. Patients unable to complete the study survey due to the severity of their medical condition were excluded.

Besides, patients admitted to the ED after calling the European Emergency Number (112) whether they were brought by an ambulance, a Paramedical Intervention Team (PIT) or a medical transport was also identified.

Inclusion and exclusion criteria are listed in Table A1. All patients gave their informed consent prior to be included in the study and the study was following the principles of the Declaration of Helsinki.

\section{Data record and analysis}

Every patient admitted to the ED benefited from ED nurse triage according to a five-level triage scale daily used in our departments, the ELISA scale [7]. Then, these patients received a questionnaire (Table A2) and were asked to complete it while waiting to be seen by an emergency practitioner.

The questionnaire was developed by a college of emergency and primary care physicians based on their experience of the field. In essence, it consisted of seven questions about the rationale and frames behind the elements involved in their decision to visit the ED, the transport they used to come to the ED and questions about their age, academic degree and diploma. Mainly, questions were constructed with a pre-defined list of potential motives but patients had the possibility to formulate free answers if they wanted to give more information.

For the study, we defined different basic concepts: a 'self-referral' was defined as a patient who decided by himself solely to present to the ED with no prior medical or paramedical advice, including retirement home or company advice, a 'GP-referral' was a patient who presented after a medical contact or a GP telephone advice, a '112-referral' was a patient who called the Emergency Number and was then referred to the ED, and finally, a 'specialist-referral' was a patient who was advised to come to the ED by a medical specialist, a paramedical contact or a third person.

\section{Statistical analysis}

The results have been encoded in a database and anonymized.

Results were expressed as means \pm standard deviations (SDs) for quantitative variables and as counts and proportions (\%) for qualitative variables. Mean values for age between the two sites were compared by Student t-test. Proportions were compared by the chisquare test or Fisher's Exact Test when necessary. Results were considered statistically significant at the $5 \%$ critical level $(P<0.05)$. The analyses were carried out using $\mathrm{R}$ software (version 3.4.1).

\section{Results}

\section{Population characteristics}

During the study, 2002 patients eligible for the study were admitted in the two ED centers. From these, 1999 patients completed the survey questionnaire, 3 were lost and 54 were excluded because of missing data. As a consequence, the study population involved 1945 participants, 949 (48.4\%) from CHUNDB and 996 (51.2\%) from CHUST facility. The mean age of the study population was $39.8 \pm 24.55$ years old $(32.8 \pm$ 21.35 in CHUST and $46.5 \pm 25.71$ in CHUNDB center). Of note is that $96.2 \%$ acknowledged having a general practitioner for their day to day follow up. Different characteristics of the population are shown in Table A3.

\section{Patient referral mechanism to hospital}

We analyzed the flow pathway to ED admission of the different patients, whether they were self-referred, referred by a general practitioner, a specialist or after contact with the 112 emergency dispatching number. We noted that the majority of ED incomings resulted from self-referral process $(68.2 \%, n=1326), 16.6 \%$ of patients were referred by their GP $(n=323)$ and only $6.63 \%(n=129)$ were admitted to the ED after calling the European Emergency Number. A few patients (8.60\%) were admitted according to the advice of a hospital specialist or a third person $(n=167)$.

We also noticed that $91.2 \%(n=1774)$ of the population use their own vehicle and only $8.80 \%(n=171)$ 
requested the help of rescue services. Among the selfreferred population ( $n=1326), 99.3 \%$ used their own vehicle $(n=1317)$ and $0.7 \%$ called an ambulance ( $n$ $=9$ ). As regards the population referred by a GP $(\mathrm{n}=$ $323), 85.7 \%$ presented to the ED by their own $(n=277)$ and $14.3 \%$ by an ambulance $(n=46)$. Concerning the 112 -referred patients $(n=129), 100 \%$ were referred to the ED by an ambulance. Finally, among the population referred by a specialist ( $n=167), 95.8 \%$ presented by their own $(n=160)$ and $4.2 \%$ called an ambulance $(n=7)$.

\section{Patient academic degree and diploma}

In the global population, $18.3 \%$ of patients only went to primary school or did not follow any educational program ( $n=357), 52.3 \%$ got a high school diploma ( $n=1017$ ) and finally, $29.4 \%$ of the population got a university or a post graduate diploma $(n=571)$. In the self-referred population, proportions of academic degrees and diplomas are similar $(61.1 \%$ for primary school, $71.5 \%$ for high school and $66.7 \%$ for University/Graduate school). Similar proportions are also found in the GP and specialist-referred populations. However, in the 112-referrals, we found a significant difference in proportions (13.4\% for primary school, $5.3 \%$ for high school and $4 / 7 \%$ for University/Graduate school). Different academic degrees and diplomas according to the referral process and the patient's motives of self-referral are displayed in Tables A4 and A5.

\section{Rationale for ED incoming in the self-referred population (Table A6)}

About half of the self-referrals (51.3\%) declared that they thought the ED was appropriate for their current problem. Another frequently mentioned frame was the accessibility of the emergency room for $23.8 \%$ of the patients $(n=315)$. A third thought expressed $(15.3 \%$, $\mathrm{n}=203$ ) was the feeling that specialized care was needed or because the patients were being followed by a specific service from this hospital. Finally, $4.22 \%$ (n $=56$ ) of the population explained that they came to the ED because of the stress and $4.6 \%(n=61)$ because they felt confident about being cared in the chosen hospital. Only $0.83 \%(n=11)$ of the patients explained that they came because of financial concerns.

The distribution of the rationales of ED incoming was found to be different according to the presentation site ( $p=0.007)$. In the CHUNDB site, accessibility motive was more frequently reported $(26.7 \%)$ than in the CHUST site (20.9\%). Conversely, patients presented more frequently in the CHUST site for the reputation (6.11\%) than in the CHUNDB site (3.0\%).

The rationale for ED incoming in the self-referred population and period of the day is displayed in
Table A7. Two periods were identified: daytime during the week (8 AM to $6 \mathrm{PM}$ ) and out-of-hours periods (6 PM to $8 \mathrm{AM}$ and the whole weekend). Interestingly, we noticed a difference for the accessibility motive between daytime $(27.1 \%)$ and out-of-hours periods (20.3\%). Likewise, admissions according to an important stress were more frequently reported during out-of-hours periods (6.3\%) as compared with $2.32 \%$ during daytime.

\section{Discussion}

As previously reported, the present study confirms that most incoming ED patients are self-referred patients. These patients did not take prior advice from their GP or call the 112 European emergency number to build or confirm their decision [8]. Interestingly, we noticed that almost all these patients had a regular family practitioner [9]. Mainly, self-referred patients use their own vehicle to come to the ED rather than call an ambulance, as for the GP and specialist-referred patients. Contrariwise, Emergency Number-referred population is associated with patients exclusively admitted by ambulance.

Academic degrees and diplomas do not seem to play a major role in self-referred patients' frames for coming to the ED. However, in the global population, lower degrees of diploma seem to be associated with a more frequent use of the Emergency Number.

Considering the drivers and rationale behind patients' decision to walk-in the ED rather than using primary care resources, we identify six main cognitive frames.

About one-half of these patients implicitly perceived that ED was the most suitable place for taking care of their acute health-care problem, perceived as 'an emergency' one. Others have described the same motive as being a key-element in patients' decisionmaking process [4-6,10-12]. When it comes to analyze whether or not patients' perceptions of their illness are really correlated with the actual degree of urgency, most studies found it difficult to classify patients' consultation acuity level on reliable and reproducible methods $[4,13]$. Moreover, there is still no gold standard to define what an inappropriate visit is or how to identify patients who could be diverted safely from ED to PCP facilities safely, without having seen a physician.

The second assumption reported by our patients 'cohort was the accessibility of the ED (23.8\%). Accessibility of care is a complex concern in many countries, covering several aspects notably in terms of time or distance. Patients frequently complain of PCP lack of availability or the difficulties encountered when it comes to get unscheduled appointments. Such situations might have contributed to decrease patients' confidence in the first line of care. It should be mentioned however that there is still debate on the 
appropriate way to increase primary care availability about the how, where and when. Indeed, some authors have advocated the fact that increasing accessibility to primary care will only transferred the problem $[6,11,14,15]$.

Paradoxically, our results highlight a trend to a more reduced PCP accessibility during daytime $(27.1 \%)$ as compared with out-of-hours (20.3\%) periods. This finding could result from the current organization of healthcare or because of their increased workload due to the increasing shortage of their profession [2]. Indeed, during out-of-hours periods, regulation systems have been established in Belgium and probably, interact favorably with these results [16-18]. Likewise, other countries have noticed such similar effects $[19,20]$.

The seek of immediate specialized care appeared as another element for ED attraction. Some patients with chronic or atypical diseases acknowledged the frame of coming to the ED as a bridge for getting specific care related to their chronic condition (15.3\%). Such an assumption has been reported in several international studies, describing the use of EDs as a vector for quicker overspecialized advice and assessment [6].

In the same way, hospital reputation seemed to motivate directly EDs attendance because patients felt more confident with the hospital institution than GP (4.6\%), a factor also recognized earlier [6].

This effect should also be considered as relates to panic-driven patients who admit coming to the ED without considering the other available care options $(4.22 \%)$, only because the fear about their condition make them take impulsive decision. In that view, we noticed that this stress-related behavior was prevalent during out-of-hours periods.

Finally, in our cohort, financial concerns did not seem to play a relevant role, although payment methods in primary care (immediate payment) and emergency care (delayed) are different. We found that these financial concerns represent a negligible part of the reasons invocated for ED request $(0.83 \%)$. Such a motivation should be further investigated in different hospital centers, on larger cohort under various healthcare organizations and countries before making any definite conclusion about it [6], but report by Lee et al. shared the same insight of small proportion of EDs attendance for financial worries [9].

On the basis of these observations, several proposals could be considered to cope with the issues related to self-referred patients. Apart from immediate life-threatening conditions, patients coming to the EDs seem to have an inaccurate perception of their illness severity. In that view, a better interface allowing patients to get the proper medical health-care information could improve their fears and doubts [12]. Hence, considering the widespread use of devices allowing web access, interactive tools or smartphone applications could be developed to offer professional advice on their complaints and guide them to the best suitable level of care, as previously described in the literature $[21,22]$. However, such tools question about safety, personal data protection, proper validation, and accessibility [23].

As concerns primary care physicians' accessibility in modern healthcare world, several authors have advocated the efficiency of primary health-care facilities located near EDs to alleviate ED attendance with patients in need of primary care. This method has been experienced in some location in Belgium and Europe with hopeful and reliable results $[6,9,12,16,24-29]$.

No matter how accessibility is developed, there is an urgent need of validated triage tools allowing to redirect patients from EDs to primary health-care facilities without prior ED physician consultation. Such tools are currently not available even if previous studies have already suggested some opportunities $[9,14]$. Of great concern is that patients seem to agree with this kind of proposition as suggested in several studies questioning patients walking-in to the ED about the possibility of a redirection to primary care services $[12,25]$.

\section{Limitations}

Analysis and interpretation of the results from this mono-centric study with a limited cohort deserve caution. Further researches on a larger cohort could be beneficial to complete these current results.

Moreover, a bias in the study is probably represented by the fact that the diagnosis and patient's condition history were not investigated. Indeed, the chronicity or the acuity of the condition that has led the patient to the ED was not taken into account. Patients could have been seen by different doctors for the same condition and then decided to come to the ED by their own and were yet considered as self-referrers.

\section{Conclusion}

Management of patients flows in need of unscheduled care is a complex and difficult concern for emergency and primary care physicians. Patients perception of their illness severity plays an important role in their choice to use the ED. Moreover, accessibility is another important motivation for patients ED incoming. These two factors are raising the importance of the implementation of information and regulation tools to address the problem.

\section{Disclosure statement}

No potential conflict of interest was reported by the authors. 


\section{ORCID}

Jean-Christophe Servotte (iD) http://orcid.org/0000-0002-

5153-3822

Anne-Françoise Donneau (D) http://orcid.org/0000-00025385-6289

\section{References}

[1] Filippatos G, Karasi E. The effect of Emergency Department crowding on patient outcome. Health Sci J. 2015;9:1-6.

[2] Van Den Heede K, Dubois C, Devriese S, et al. Organisation and payment of emergency care services in Belgium: current situation and options for reform. Brussels: Belgian Health Care Knowledge Centre (KCE);2016. (Report 263Cs).

[3] Cartier T, Ryssaert L, Bourgueil Y. Belgium. In: Kringos D, Boerma W, Hutchinson A, et al. editors. Building primary care in a changing Europe: case studies. United Kingdom (UK): European Observatory on Health System and Policies; 2015. p. 9-17.

[4] Akbulut $Y$, Tatar M, Cetinyürek A, et al. Non-urgent use of the emergency department: a quantitative evaluation from a patient perspective. J Manag Marketing Healthc. 2008;1(4):389-399.

[5] Lobachova L, Brown DFM, Sinclair J, et al. Patient and provider perceptions of why patients seek care in emergency departments. J Emerg Med. 2014;46 (1):104-112.

[6] Lega F, Mengoni A. Why non urgent patients choose emergency over primary care services? Empirical evidence and managerial implications. Health Policy. 2008;88(2-3):326-338.

[7] Jobé J, Ghuysen A, Gérard P, et al. Efficiency of a French-language triage algorithm in the emergency department. Crit Care. 2011;15(Suppl 1):455.

[8] Carrasco V, Baubeau D. Les usagers des urgences: premiers résultats d'une enquête nationale. Etudes Et Résultats. 2003;212:1-8.

[9] Carrasco V, Baubeau D. Motifs et trajectoires de recours aux urgences hospitalières. Etudes Et Résultats. 2003;215:1-12.

[10] Lee A, Lau FL, Hazlett CB, et al. Factors associated with non-urgent utilization of accident and emergency services: a case control study in Hong Kong. Social Sci Med. 2000;51:1075-1085.

[11] Uscher-Pines L, Pines J, Kellermann A, et al. Deciding to visit emergency department for non-urgent conditions: a systematic review of the literature. Am J Manag Care. 2013;19(1):47-59.

[12] Coster JE, Turner JK, Bradbury D, et al. Why do people choose emergency and urgent care services? A rapid review utilizing a systematic literature search and narrative synthesis. Acad Emerg Med. 2017;24 (9):1137-1149.

[13] Durand AC, Palazzolo S, Tanti-Hardouin N, et al. Non urgent patients in emergency departments: rational or irresponsible consumers? Perceptions of professionals and patients. BMC Res Notes. 2012;5(525):1-9.
[14] Mackichan F, Brangan E, Wye L, et al. Why do patients seek primary medical care in emergency departments? An ethnographic exploration of access to general practice. BMJ Open. 2017;7:e013816.

[15] Colliers A, Remmen R, Streffer ML, et al. Implementation of a general practitioner cooperative adjacent to the emergency department of a hospital increases the caseload for the GPC but not for the emergency department. Acta Clin Belg. 2017;72(1):49-54.

[16] Belche JL, Berrewaerts MA, Burette $P$, et al. Retrospective analysis of a suburban out-of-hours clinic in belgium. Acta Clin Belg. 2014;69 (5):341-347.

[17] Brasseur E, Ghuysen A, Donneau AF, et al. Reliability of a new french-language triage algorithm for out-ofhours primary care calls: the salomon rule. Crit Care. 2015;19(Suppl 1):P406.

[18] Brasseur E, Pâques F, Ghuysen A, et al. Algorithme de régulation des appels de médecine générale. Acta Clin Belg. 2013;68(6):P487.

[19] Munro J, Nichol J, O'Cathain A, et al. Impact of NHS direct on demand for immediate care: observational study. BMJ. 2000;321:150-153.

[20] Dunt D, Wilson R, Day SE, et al. Impact of telephone triage on emergency after hours GP Medicare usage: a time series analysis. Aust New Zealand Health Policy. 2007;4:21.

[21] Berchet C, Nader C The organisation of out-of-hours primary care in OECD countries. OECD Health Working Papers. 2016;89:1-26.

[22] Verzanvoort N, Teunis T, Verheij T, et al. A self-triage for acute primary care via a smartphone application: practical, safe and efficient?. Plos One. 2018;13(6):e0199284.

[23] Tonsaker T, Bartlett G, Trpkov C. Information sur la santé dans internet. Can Fam Physician. 2014;60 (5):419-420.

[24] Chmiel C, Huber CA, Rosemann T, et al. Walk-ins seeking treatment at an emergency department or general practitioner out-of-hours service: a cross-sectional comparison. BMC Health Serv Res. 2011;11:94.

[25] Gentile S, Vignally P, Durand AC, et al. Non urgent patients in the emergency department? A french formula to prevent misuse. BMC Health Serv Res. 2010;10:66.

[26] Van Uden CJ, Crebolder HFJM. Does setting up out-ofhours primary care cooperatives outside a hospital reduce demand for emergency care? Emerg Med J. 2004;21(6):722-723.

[27] Van Gils-Van Rooij ESJ, Joris Yzermans C, Broekmans SM, et al. Out-of-hours care collaboration between general practitioners and hospital emergency departments in the Netherlands. J Am Board Fam Med. 2015;28:807-815.

[28] Rutten M, Vrielink F, Smits $M$, et al. Patient and care characteristics of self-referrals treated by the general practitioner cooperative at emergency-care-accesspoints in the Netherlands. BMC Fam Pract. 2017;18:62.

[29] Thijssen WA, Wijnen-van Houts M, Koetsenruijter J, et al. The impact on emergency department utilization and patient flows after integrating with a general practitioner cooperative: an observational study. Emerg Med Int. 2013; 2013:364659. 


\section{Appendices}

Table A1. Inclusion and exclusion criteria.

- Every patient who presented on his own to the Emergency Department.

- Every patient referred to the Emergency Department by a primary care physician or a telephone triage nurse.

- Every patient referred to the Emergency Department after calling the European Emergency Number (either by ambulance, paramedical intervention team or medical transport)
- Patients unable to complete the study survey due to their medical condition.

- Patients $<16$ years old admitted to the ED with no relative

Table A2. Study's questionnaire.

\begin{tabular}{|c|c|}
\hline Motive of presentation & (101, \\
\hline ELISA Triage & $\mathrm{U} 1-\mathrm{U} 2-\mathrm{U} 3-\mathrm{U} 4-\mathrm{U} 5 \mathrm{~A}-\mathrm{B}-\mathrm{C}-\mathrm{D}$ \\
\hline General Practitioner & Yes - No \\
\hline Academic Degree/Diploma & 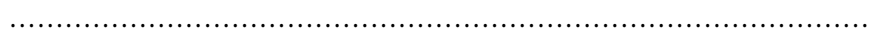 \\
\hline How did you to come to the Emergency Department? & $\begin{array}{l}\text { (1) Own vehicle, public transport, etc. } \\
\text { (2) Ambulance. }\end{array}$ \\
\hline How were you referred to the Emergency Department? & $\begin{array}{l}\text { (1) Self-referred. } \\
\text { (2) After a contact with my general practitioner. } \\
\text { (3) After a contact with the Emergency Number } 112 . \\
\text { (4) Other (specialist, nursing home, etc.): }\end{array}$ \\
\hline Why did you choose to come to the Emergency Department? & 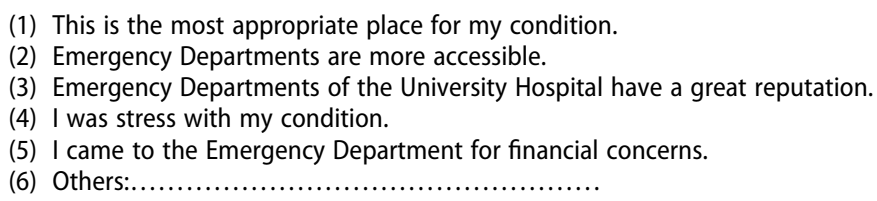 \\
\hline
\end{tabular}

Table A3. Characteristics of the studied population globally and in each site.

\begin{tabular}{lccc}
\hline CHARACTERISTICS & 2 SITES & CHUST & CHUNDB \\
\hline AGE & $n=1945$ & $n=996$ & $n=949$ \\
$<16$ years & $18.15 \%(n=353)$ & $5.72 \%(n=57)$ & $31.20 \%(\mathrm{n}=296)$ \\
$16-74$ years & $71.36 \%(\mathrm{n}=1388)$ & $83.04 \%(\mathrm{n}=827)$ & $59.11 \%(\mathrm{n}=561)$ \\
$>74$ years & $10.49 \%(\mathrm{n}=204)$ & $11.24 \%(\mathrm{n}=112)$ & $9.69 \%(\mathrm{n}=92)$ \\
Mean \pm SD & $39.8 \pm 24.55$ & $32.8 \pm 21.35$ & $46.5 \pm 25.71$ \\
GENDER & & & \\
Men & $49.87 \%(\mathrm{n}=970)$ & $52.81 \%(\mathrm{n}=526)$ & $46.78 \%(\mathrm{n}=444)$ \\
Women & $50.10 \%(\mathrm{n}=975)$ & $47.18 \%(\mathrm{n}=470)$ & $53.20 \%(\mathrm{n}=505)$ \\
\hline
\end{tabular}

Table A4. Different academic degrees and diplomas according to patients' referral process to the emergency department.

\begin{tabular}{|c|c|c|c|c|}
\hline Diploma & $\begin{array}{l}\text { Self-referred } \\
(n=1326)\end{array}$ & $\begin{array}{l}\text { GP-referred } \\
(\mathrm{n}=323)\end{array}$ & $\begin{array}{l}\text { 112-referred } \\
(\mathrm{n}=129)\end{array}$ & $\begin{array}{c}\text { Specialist-referred } \\
(\mathrm{n}=167)\end{array}$ \\
\hline Primary school or less $(n=357)$ & $61.1 \%(n=218)$ & $17.4 \%(n=62)$ & $13.4 \%(n=48)$ & $8.1 \%(n=29)$ \\
\hline High school $(n=1017)$ & $71.5 \%(n=727)$ & $14.8 \%(n=151)$ & $5.3 \%(n=54)$ & $8.4 \%(n=85)$ \\
\hline University/Graduate school $(\mathrm{n}=571)$ & $66.7 \%(n=381)$ & $19.3 \%(n=110)$ & $4.7 \%(n=27)$ & $9.3 \%(n=53)$ \\
\hline
\end{tabular}

Table A5. Different academic degrees and diplomas according to the self-referred patients' motives of presentation.

\begin{tabular}{|c|c|c|c|c|c|c|}
\hline Diploma & $\begin{array}{l}\text { Suitability } \\
(n=680)\end{array}$ & $\begin{array}{c}\text { Accessibility } \\
(n=315)\end{array}$ & $\begin{array}{l}\text { Reputation } \\
(\mathrm{n}=58)\end{array}$ & $\begin{array}{l}\text { Stress } \\
(n=56)\end{array}$ & $\begin{array}{l}\text { Financial concerns } \\
\qquad(\mathrm{n}=11)\end{array}$ & $\begin{array}{c}\text { Others } \\
(n=203)\end{array}$ \\
\hline Primary school or less $(n=218)$ & $50.5 \%(n=110)$ & $22.5 \%(n=49)$ & $5 \%(n=11)$ & $4.6 \%(n=10)$ & $1.4 \%(n=3)$ & $16 \%(n=35)$ \\
\hline High school $(n=727)$ & $52.7 \%(n=383)$ & $23.1 \%(n=168)$ & $4.3 \%(n=31)$ & $4.1 \%(n=30)$ & $0.8 \%(n=6)$ & $15 \%(n=109)$ \\
\hline University/Graduate school $(\mathrm{n}=381)$ & $49.1 \%(n=187)$ & $25.7 \%(n=98)$ & $5 \%(n=19)$ & $4.2 \%(n=16)$ & $0.5 \%(n=2)$ & $15.5 \%(n=59)$ \\
\hline
\end{tabular}


Table A6. Self-referrals motives of admission to the ED.

\begin{tabular}{lccc}
\hline & 2 SITES & CHUST & CHUNDB \\
MOTIVES & $\mathrm{n}=1326$ & $\mathrm{n}=671$ & $\mathrm{n}=655$ \\
\hline SUITABILITY & $51.3 \%(\mathrm{n}=680)$ & $52.9 \%(\mathrm{n}=355)$ & $49.6 \%(\mathrm{n}=325)$ \\
ACCESSIBILITY & $23.8 \%(\mathrm{n}=315)$ & $20.9 \%(\mathrm{n}=140)$ & $26.7 \%(\mathrm{n}=175)$ \\
REPUTATION & $4.6 \%(\mathrm{n}=61)$ & $6.11 \%(\mathrm{n}=41)$ & $3.00 \%(\mathrm{n}=20)$ \\
STRESS & $4.22 \%(\mathrm{n}=56)$ & $3.28 \%(\mathrm{n}=22)$ & $5.19 \%(\mathrm{n}=34)$ \\
FINANCIAL CONCERNS & $0.83 \%(\mathrm{n}=11)$ & $1.00 \%(\mathrm{n}=7)$ & $0.6 \%(\mathrm{n}=4)$ \\
OTHERS & $15.3 \%(\mathrm{n}=203)$ & $15.8 \%(\mathrm{n}=106)$ & $14.9 \%(\mathrm{n}=97)$ \\
\hline
\end{tabular}

Table A7. Different motives according to the period of the day.

\begin{tabular}{lccc}
\hline & GLOBAL & DAYTIME & OUT-OF-HOURS \\
\hline REASONS & $\mathrm{n}=1326$ & $\mathrm{n}=694$ & $\mathrm{n}=632$ \\
SUITABILITY & $51.3 \%(\mathrm{n}=680)$ & $49.4 \%(\mathrm{n}=343)$ & $53.3 \%(\mathrm{n}=337)$ \\
ACCESSIBILITY & $23.75 \%(\mathrm{n}=315)$ & $26.9 \%(\mathrm{n}=187)$ & $20.3 \%(\mathrm{n}=128)$ \\
REPUTATION & $4.6 \%(\mathrm{n}=61)$ & $3.74 \%(\mathrm{n}=26)$ & $5.54 \%(\mathrm{n}=35)$ \\
STRESS & $4.22 \%(\mathrm{n}=56)$ & $2.31 \%(\mathrm{n}=16)$ & $6.32 \%(\mathrm{n}=40)$ \\
FINANCIAL & $0.83 \%(\mathrm{n}=11)$ & $0.43 \%(\mathrm{n}=3)$ & $1.27 \%(\mathrm{n}=8)$ \\
OTHERS & $15.3 \%(\mathrm{n}=203)$ & $17.1 \%(\mathrm{n}=119)$ & $13.3 \%(\mathrm{n}=84)$ \\
\hline
\end{tabular}

